\title{
PSYCHIATRY AND THE CULTURE OF POVERTY*
}

John J. Honigmann

The University of North Carolina

A psychiatrist who designates behavior as disordered, deviant, or sick and identifies the antecedent social conditions of such behavior as stressful, disorganized, or disintegrated necessarily and properly makes value judgments. However considered, sympathetic, well-intentioned, and technically couched his opinions may be, he judges some behavior and its attendant circumstances to be less desirable than others. Whether a clinical psychiatrist asks himself in which readymade disease category the symptoms fit or, in the manner of the existential psychiatrist, he attempts to understand the behavior from the patient's inner world - that is, deals with the situation the patient confronts and the goals toward which he is striving - the psychiatrist sees something undesirable in the goals which the other person pursues. Or else, he sees the patient's means of striving, the inordinately great or miniscule amount of energy he expends in adaptation, his emotionally inappropriate tone of behavior, or the character of his relationship with other people to be somehow wrong. Just as the law sees a lawbreaker deviating from legal norms, the psychiatrist views his patient to be deviant with respect to some ideal pattern which may be left unvoiced or inexplicit. My objest is not to question the propriety of such professional judgments but to determine what might be called their social basis and to call attention to certain consequences that follow.

*A considerably longer version of this paper was prepared for the University of Kentucky Centennial Conference on Cross-cultural Psychiatry and Psychoethnology.
Psychiatric judgments are value judgments made by some members of a class-divided society about other members. In our highly diversified social system, psychiatrists are primarily rooted in one sociocultural segment, which I will take the liberty of calling the middle-class (or middle-class culture). More specifically, the psychiatrist embodies a professional variant of American middle-class culture. I don't mean that the social classes possess relatively self-contained, total cultures. They are subcultures or, even more precisely, they are distinguished by cultural specialties and alternatives which, taken together with our cultural universals, make up the United States, culturally speaking. The psychiatrist's ability to make value judgments authoritatively about his fellow citizen's activities - to make them stick occurs by virtue of his professional status which confers on him power over the person whom he diagnoses. Note one consequence that follows. The psychiatrist possesses power to implement certain values and standards (namely his own) over other, competing values and standards that he has reason to regard as dangerous to the patient or for society.

Anyone who makes expert judgments - management consultants, economists, engineers, or TV repairmen-always occupies a particular position in a structure of unequal knowledge and values. The expert has a vested interest in a given set of norms or in a special way of life. Equally so, a psychiatrist. He speaks from a special vantage point when he appraises homosexuality, extreme suspiciousness, or dread as 
sick or undesirable. Now, the question I wish to concentrate on is this: do not the psychiatrist's values and diagnostic judgments sometimes represent behavior norms that stem from his social-class position? If, as to me seems likely, they do embody class-bound behavioral values call them middle-class values for brevity's sake - then when he deals with patients of another, especially lower, social class isn't he judging another way of life by comparing it unfavorably with his own? As a result, lower-ranking people are more often likely to impress him with poorer mental health than people who act according to his own norms.

If my hypothesis holds true, it offers one but not the only reason why in large-scale epidemiological surveys lower class respondents tend to cluster toward the seriously impaired end of the mental health spectrum. For example, findings of the Midtown Manhattan Study'. indicate that mental health between three socioeconomic levels - high, middle, and low - varies much more than might be expected. In operational terms, persons of low socioeconomic status risk coming through a psychiatric screening with worse mental health ratings than persons of middle or high status who have experienced the same, measured amount of lifetime stress. Stress scores $d o$ climb from high socioeconomic status to low, but mental health risk increases still faster. Why do respondents of low socioeconomic status come through psychiatric screening with worse mental health? One reason may be that high status people react to stress in predominantly neurotic fashion, becoming nervous, restless, obsessionally worried, and so on. They become mentally ill in ways that are tightly controlled and therefore consistent with their middle- and upper-class values. People of low socioeconomic status, on the other hand, respond to stress in ways compatible with their isolation, passivity, dependence, mistrust, and social inadequacy. Their symptoms exaggerate, or at least utilize, the class-bound behavior patterns that they also reveal in normal situations. But why should lower-class ways of getting sick be worse than middle-class ways of getting sick? Middleclass-bound psychiatrists judge them so. In their screening they more frequently give the interviews of respondents of relatively low socioeconomic status worse mental-health ratings than they assigned to subjects of higher rank.
By the standards of their profession they undoubtedly felt fully justified in evaluating them as worse off, but the fact remains that they evaluated lower-class modes of adaptation as worse than middle- and upper-class modes and so discovered that mental health fares worse as one goes down the social-class ladder. No doubt it was worse - according to the standards that the psychiatrists used. I suggest that those standards were contaminated by the evaluator's own classbound values to a degree. I suspect that his values blocked him from obtaining a fuller, if not truer, view of the people whom he judged. ${ }^{2}$ When psychiatrists include their class-bound values in evaluating personality disorder, people who show strain by acting out or falling to pieces emotionally and cognitively, as lowerclass people predominantly do, must be judged as worse off than people who feel unworthy or who constantly visit the doctor with difficult stomachs.

To the value judgments that a clinical psychiatrist makes when he designates a person's behavior as disordered, the social psychiatrist adds professionally informed value judgments that cover the patient's social setting. The stress concept or some analogous notion provides the bridge which connects personality disorder to etiologically significant, antecedent social conditions. When used in a psychological sense, stress and its counterpart, strain, are applied figuratively or analogically to the meaning they hold in engineering. Poverty, broken homes, a person's failure to achieve vital goals, cognitive dissonance, and many more experiences are figuratively conceived as acting like physical forces which wear down physical materials. Stress is certainly ubiquitous in human life but social scientists believe that it inheres much more heavily in some sectors of social spaceespecially in some strata of a stratified community - than in others. The Midtown Study's recent attempt to test this hypothesis by measuring stress objectively led to interesting results. ${ }^{3}$ The study inquired about and counted such stressors as poor physical health in childhood, broken homes, economic deprivation in childhood, current worry about work or about socioeconomic status and marital worries. Note that the designers of this research not only assumed stress to be objectively identifiable butalso that it could be quantified. Some 1600 carefully 
selected Manhattan adults each received a stress score based on factors in his life like those I just mentioned, including whether he worried about work, overwork, getting ahead, and the cost of living, and whether he enjoyed only few or no social affiliations with neighbors, close friends, or co-members in organizations. How surprised the investigators were to learn that stress scores didn't vary much between high, middle, and low social strata. People of low socioeconomic status scored an average of 5.7; in middle strata they scored a 5.3 average, and in higher levels, 4.7. By the social psychiatrists' own admission, they had probably over-estimated exposure to stress in lower socioeconomic levels.

This discovery suggests that middle-class social psychiatrists exaggerate the stressful components of lower-class life. To be sure the poor suffer from bad housing, frequent aggression, illness, and many kinds of failure, exploitation, and victimization. They do so to such an extent that these are earmarks of the culture of poverty. But they are undoubtedly not the sole properties of that culture. What in fact do middle-class people really know about the culture of poverty? Practically all the sociologically and anthropologically derived information we possess exudes a class-bound bias and probably seriously distorts that many-faceted culture by abstracting only its misery. Balanced accounts, like The Urban Villagers by Herbert J. Gans which I would exempt from my generalization, are all too rare. As Margaret Mead once said, the social sciences following the lead of psychiatry prefer to listen almost solely for distortion. ${ }^{4}$ They do so with both ears, paying practically no heed to cultural patterns and social arrangements that might compensate people for their undeniably harsh phases of existence. In their biased approach, social scientists seriously overlook possibilities for new learning. By emphasizing only one side of the culture of poverty, they block off unexpected discoveries of new facts.

Returning to the Midtown Study and its attempt to measure stress objectively in high, middle, and low socioeconomic strata, can such a procedure be sound when the indicators of stress have been subjectively determined by middleclass observers? Furthermore, if the same observers judge the culture of poverty by their own deeply cherished, class-bound standards, can they ever see much more than predominant misery, squalor, and other deplorable traits? The facts in such cases may not mean the same thing to the actors and the persons doing the study. The very variables an investigator selects, like little communication in the home, mutual misunderstanding, and lack of togetherness in the family, betray his values.

Social psychiatrists confront a problem that belongs to every other social science discipline as well. How can we learn better to understand significantly different people and communities without imposing too much of ourselves on the material we wish to comprehend? To resolve that problem better requires utilizing a maximum of the structure that, as Sapir puts it, is inherent in the data being observed. ${ }^{5}$ This doesn't mean letting an inhabitant of the culture of poverty dictate his own ethnography. The result would also be highly biased. What is called for is stretching and improving our methods to incorporate the inhabitant's experience and pattern of life as fully and fairly as possible.

Descriptive analyses of society or personality can never pretend to be faithful mirrorings of external reality nor should they be regarded as direct translations of one realm of experience into another. Psychiatric views of the culture of poverty, like any formulation of individual personality or culture history, represent a dialectic resolution of a state of tension that has been generated between the observer and the material he seeks to understand. A description or analysis is a tentative synthesis of that tension, a temporary resolution of a prolonged state of opposition. The tension may return as soon as the observer or others disagree with the formulation, either because new facts have come to light or fresh concepts have been coined that render the existing account unsatisfactory and no longer tenable. In criticizing the class-bound, ethnocentric value judgments of psychiatry I don't offer as a substitute some certain path to fully objective, immutable truth. Truth in psychiatry and the other disciplines that study human behavior consists of a relatively stable equilibrium that has been established between an observer and his colleagues after he has succeeded in resolving to his own satisfaction the tension that existed between himself and the subject matter he sought to understand. 
1 Thomas S. Langner and Stanley T. Michael, Life Stress and Mental Health, New York, 1963; pp. 87-88, and Ch. $15,16$.

${ }^{2}$ Frank E. Hartung, "Manhattan Madness: The Social Movement of Mental Illness," Sociological Quarterly, 4, 1963; pp. 261-272.

${ }^{3}$ Thomas S. Langner and Stanley T. Michael, Op. Cit.
${ }^{4}$ Margaret Mead, "Some Relationships Between Social Anthropology and Psychiatry." In Franz Alexander, ed., Dynamic Psychiatry, Chicago, 1952.

${ }^{5}$ Richard J. Preston, Imposed and Inherent Cultural Structures and Writings of Edward Sapir, M. A. thesis, Department of Anthropology, University of North Carolina, Chapel Hill, 1964. 